\title{
Historical perspectives of The American Association for Thoracic Surgery: John W. Strieder (1901-1993)
}

\author{
Cameron D. Wright, MD
}

John William Strieder, 52nd president of The American Association for Thoracic Surgery (AATS), was born on June 6, 1901, in Boston. His family lived in Roxbury and owned a cigar box factory. He was raised by his mother after his father died when he was an early teen. Strieder enjoyed reading the classics and maintained that interest throughout his life. His initial educational focus was engineering, and he graduated from the Massachusetts Institute of Technology in 1922 (Figure 1); however, his interests migrated toward medicine. After graduation from Harvard Medical School in 1926, he started in pathology at the New England Deaconess Hospital and then continued as a surgical resident on the Fifth (Harvard) Surgical Service at the Boston City Hospital from 1927 to 1929 and the Boston Lying-In Hospital the following year. In 1930, Strieder contracted tuberculosis and spent nearly a year as a patient at the Trudeau Sanatorium in New York. Years later, Strieder regaled his children with stories of sleeping in a bed on an open porch in the winter as part of his therapy and of a devoted nurse who knitted him a nose warmer, which he wore while he slept! He stayed on for 2 years after his cure as an assistant resident, an experience that convinced him to become a thoracic surgeon, like many other budding thoracic surgeons of that era.

Dr Strieder applied to and was accepted at the only formal thoracic surgery residency in 1933, the University of Michigan program of Dr John Alexander (17th AATS president), where he learned the intricacies of collapse therapy for tuberculosis. Strieder was Alexander's 7th resident, and his first publication, near the end of his training in 1935, was with Alexander, "Multiple intercostal neurectomy for pulmonary tuberculosis: Indications and results."1 Reading this seminal article allows the modern thoracic surgeon to become immersed in the history of our specialty, but it also sounds a cautionary note on data reporting-ie, are extraordinary results always reproducible? Strieder and Alexander ${ }^{1}$ reported on 20 patients with advanced tuberculosis who were too ill for thoracoplasty. In all cases, the combination of pneumothorax, phrenic nerve crush,

\footnotetext{
From the Department of Thoracic Surgery, Massachusetts General Hospital, Boston, Mass.

Disclosures: Author has nothing to disclose with regard to commercial support.

Received for publication July 17, 2012; accepted for publication Sept 27, 2012; available ahead of print Oct 29, 2012.

Address for reprints: Cameron D. Wright, MD, Massachusetts General Hospital, Thoracic Surgery, Blake 1570, 55 Fruit St, Boston, MA 02114 (E-mail: wright. cameron@mgh.harvard.edu).

J Thorac Cardiovasc Surg 2013;145:2-4

$0022-5223 / \$ 36.00$

Copyright $(c) 2013$ by The American Association for Thoracic Surgery http://dx.doi.org/10.1016/j.jtcvs.2012.09.075
}

scalenectomy, and prolonged bed rest had failed. Posterior intercostal neurectomy was performed from the 2 nd to the 6 th nerves with crush of the 7 th to the 10th nerves in 2 stages under local anesthesia. Remarkably, 14 of 20 patients had improvement with this method of placing the lung at rest: "the homolateral hemithorax becomes virtually immobile during quiet respiration and assumes the position of full expiration." 1

While at Michigan, Strieder married Helen L. Roberts, a trainee in orthopedic surgery. After completing residency, they returned to Boston, and John entered private practice. In 1935, only 19 surgeons in the country limited their practice to thoracic surgery, and Strieder was the first in Boston. John and Helen, who died after a stroke at age 52, had 3 daughters (Figure 2). John later remarried another physician, pulmonologist Denise J. French, with whom he often collaborated on clinical articles.

Dr Strieder had a "near miss" with destiny when he made a courageous attempt to salvage a 22-year-old woman with a patent ductus arteriosus complicated by Streptococcus viridans endocarditis. ${ }^{2}$ The young woman was clearly in the process of dying when Strieder decided to ligate the ductus, despite the fact that the operation had never previously been performed. On March 16, 1937, Strieder initially attempted to encircle the ductus but wisely abandoned his attempt because of severe inflammation. Instead, he tried to obliterate the ductus with a series of plicating sutures; however, although there was considerable reduction in the lumen of the vessel, obliteration was not complete. On the evening of the $4 \mathrm{~h}$ day, the patient, who until that moment had made an uneventful recovery, suddenly vomited, arrested, and died. Autopsy revealed several small necrotic pulmonary infarcts, vegetations on the main pulmonary artery and at the orifice of the ductus, and marked narrowing of the ductus with a reduction to a lumen of only $3 \mathrm{~mm}$. Her stomach was found to be acutely dilated, which was considered the immediate cause of death. Strieder gave credit for the idea to ligate the ductus to John Munro, who had been chief of neurosurgery at Boston City Hospital years earlier.

John Munro first proposed the idea of ductus ligation in an article read before the Philadelphia Academy of Surgery on May 6, 1907. ${ }^{3}$ Remarkably, Strieder was at a dinner party in Boston at the home of Dr Donald Munro, son of John Munro, in the spring of 1937 shortly before his attempt to ligate the ductus (Robert Berger, personal communication, March 2012). Strieder presented his difficult case to Donald, who recalled that his father had published on this topic 30 years previously. Donald brought Strieder to his study, 


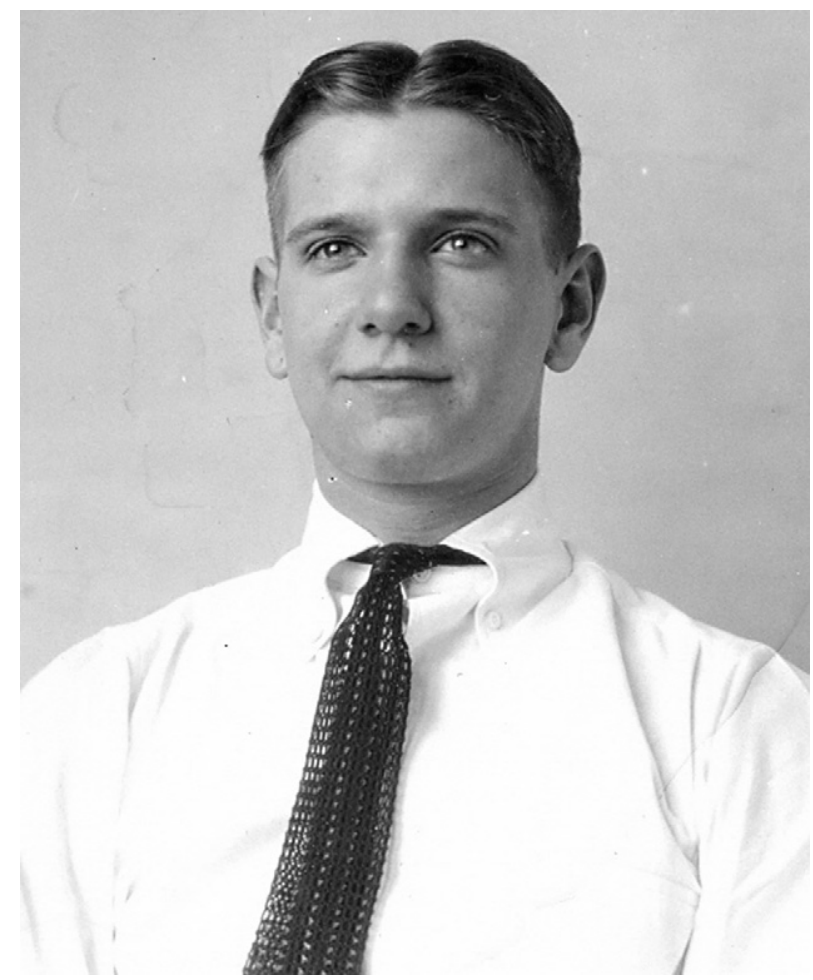

FIGURE 1. John Strieder as a college student at the Massachusetts Institute of Technology.

where he searched through his father's papers until he found the 1907 report. Together, they came up with the idea to ligate the ductus of Strieder's patient, a feat that would not be successfully performed until Robert Gross (44th AATS president) successfully ligated the ductus of a young girl with intractable heart failure on August 26, $1938 .{ }^{4}$

Dr Strieder established the first thoracic surgery residency in Boston at the Boston City Hospital in 1946 and led the division from its inception until 1967. He became

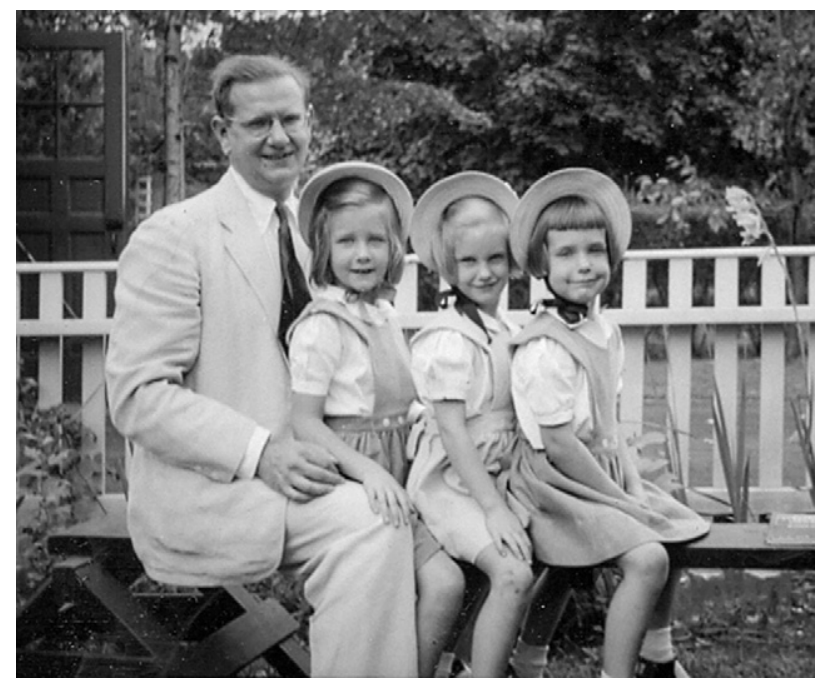

FIGURE 2. John Strieder with his 3 daughters, Merritt, Helen, and Alison.

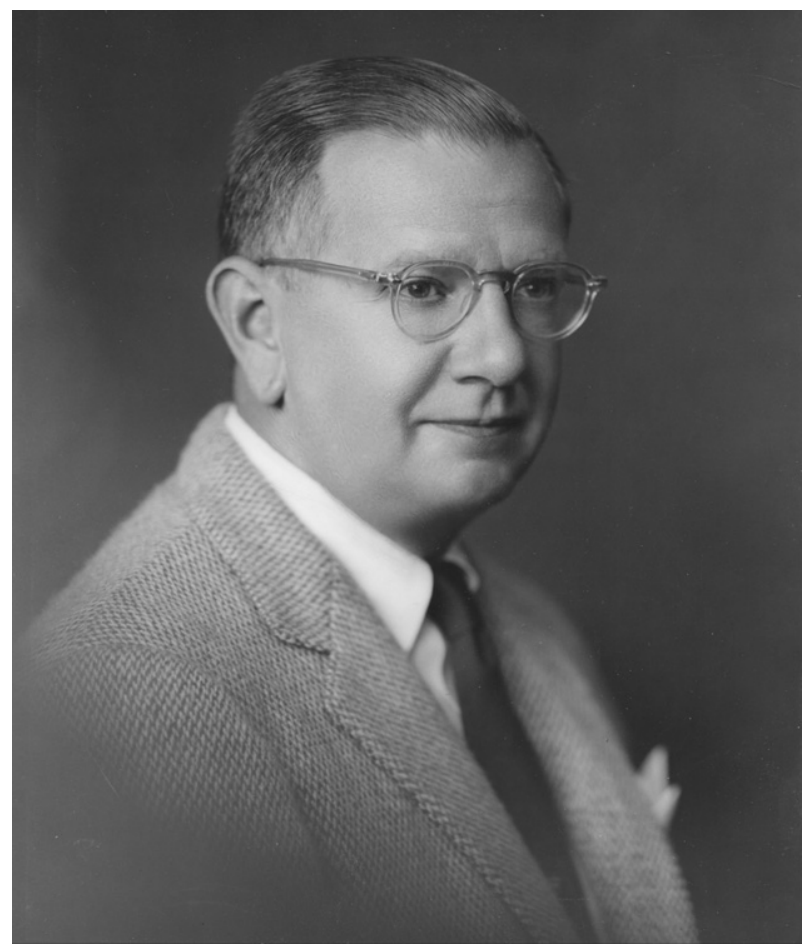

FIGURE 3. Dr Strieder in 1964, as chairman of the American Board of Thoracic Surgery.

professor of surgery at Boston University School of Medicine and was honored on his retirement with creation of the John W. Strieder Visiting Professorship in Cardiothoracic Surgery. Strieder was a director of the American Board of Thoracic Surgery and was the chair of the Board from 1963-1965 (Figure 3). His leadership on the Board emphasized standardization of training and examinations. In a soliloquy about the training in 1965, Strieder started his definition of a thoracic surgeon with, "He is truly a surgeon and something more. ..., 5

When Dr Strieder retired from the directorship of the Thoracic Surgery Service at the Boston City Hospital in 1967, a Festschrift was held in his honor. ${ }^{6}$ Strieder was noted to have a pronounced, wry sense of humor. Dr Paul Ware, his first resident, collected many anecdotes from Strieder's former residents ${ }^{6}$ :

- The following episode to me indicates the kindness and gentlemanly behavior of this man to his house officers: I had placed a closed thoracotomy tube too dependently and into the liver in a woman who had been stabbed by "a friend." His comment: "I should have taught you not to place a closed thoracotomy tube too low. Besides, homicide legally starts with the initial act."

- A certain bronchoscopy.... First the esophagus, then the pyriform sinuses, but, eventually, the glottis and triumph. Lights burned out, cord tripped over, suction tubing collapsed, specimen dropped on the floor and temporarily 
lost. Dr Strieder spoke quietly to the resident: "George, would you please dictate this note?"

- According to his then-associate Dwight Harken, the Strieder of this era could be described as "possessed of external equanimity that concealed internal turmoil betrayed only by the munching of antacid tablets."

- His practice includes many types of patients-difficult problems and difficult people, a few rich and many poor, but always a large number of close friends and immediate relatives of referring physicians.

Dr Strieder presented his AATS presidential address in Los Angeles in 1972 entitled, "Aesculapius contemplates thoracic surgery." ${ }^{7}$ In a return to his roots in the classics, Strieder used Aesculapius as a foil to discuss the state of medicine, thoracic surgery, and residency training in the early 1970s. He concluded his address as follows ${ }^{7}$ :

The sun had risen above the horizon and I was reminded of the first line of a well-known bawdy poem, "Now in the East the gleaming wheel of Phoebus' car is turning." The sunlight for a brief second became almost incandescent. The figure of
Aesculapius paled and vanished . . . "Good-bye, Aesculapius," I shouted.

Dr Strieder subsequently moved his practice to the Newton-Wellesley Hospital where he remained chief of thoracic surgery until his final retirement. He died at Newton-Wellesley at the age of 92 on October 25, 1993.

I thank Dr Strieder's daughters Helen and Merritt for sharing details of his life and family photographs.

\section{References}

1. Strieder JW, Alexander J. Multiple intercostal neurectomy for pulmonary tuberculosis: indications and results. J Thorac Surg. 1935;4:473-91.

2. Graybiel A, Strieder JW, Boyer NH. An attempt to obliterate the patent ductus arteriosus in a patient with subacute bacterial endocarditis. Am Heart J. 1938;15: $621-4$.

3. Munro JC. Ligation of the ductus arteriosus. Ann Surg. 1907;335-8.

4. Gross RE, Hubbard JP. Surgical ligation of the patent ductus arteriosus. JAMA. 1939;112:729-31.

5. Strieder JW. The training of the thoracic surgeon. Ann Thorac Surg. 1965;1:363-5.

6. Ware PF. J.W.S.: an appreciation by his first resident. Ann Thorac Surg. 1967;4: 511-3.

7. Strieder JW. Aesculapius contemplates thoracic surgery. J Thorac Cardiovasc Surg. 1972;64:169-78. 